Original Article

\title{
Incidence of cachexia in patients with advanced gastrointestinal cancer at the beginning of rehabilitation intervention
}

\author{
Yoshiteru Akezaki, RPT, PhD ${ }^{1 *}$, Masato Kikuuchi, OTR ${ }^{2)}$, Kazunori Hamada, RPT ${ }^{1)}$, \\ Mitsuhiro OOKURA, RPT, $\mathrm{PhD}^{1)}$ \\ 1) Division of Physical Therapy, Kochi Professional University of Rehabilitation: \\ 1139-3 Otu, Takaoka-machi, Tosa, Kochi 781-1102, Japan \\ 2) Department of Rehabilitation Medicine, National Hospital Organization Shikoku Cancer Center, \\ Japan
}

\begin{abstract}
Purpose] We examined the incidence of cachexia at the beginning of rehabilitation in patients with advanced gastrointestinal cancer. [Participants and Methods] Patients with gastrointestinal cancer who were prescribed physical therapy and occupational therapy by their rehabilitation doctor and completed the survey item were targeted. We administered the cancer cachexia assessment and evaluated activities of daily living, and nutritional status in all participants. [Results] There were 15 patients in the normal group, 8 in the normal low-nutrition group, 16 in the pre-cachexia group, and 57 in the cachexia group. The cachexia group showed significantly lower nutritional status, and were less able to perform activities of daily living than the normal and pre-cachexia groups. [Conclusion] The incidence of cachexia among study participants was $17 \%$ in the pre-cachexia group and $59 \%$ in the cachexia group at the beginning of rehabilitation. Patients with advanced gastrointestinal cancer may have a higher incidence of cachexia at the beginning of rehabilitation.

Key words: Activities of daily living, Gastrointestinal cancer, Rehabilitation
\end{abstract}

(This article was submitted Jul. 23, 2019, and was accepted Oct. 17, 2019)

\section{INTRODUCTION}

Approximately half of all cancer patients suffer from cachexia. Cachexia occurs in up to $80 \%$ of patients with advanced disease $^{1,2}$. Cachexia is frequently observed in patients with cancerous tumors such as lung cancer, pancreatic cancer, esophageal cancer, and stomach cancer, with a lower prevalence in patients with breast cancer and hematological malignancies ${ }^{3-7)}$. The features of cancer cachexia include weight loss, impaired physical function, and skeletal muscle atrophy ${ }^{8)}$. In addition, the activities of daily living (ADL) are compromised, and quality of life (QOL) is reduced ${ }^{9}$ ). Furthermore, cancer cachexia is considered the immediate cause of death of a large proportion of cancer patients ${ }^{10}$.

Rehabilitation may be carried out for advanced gastrointestinal cancer patients for the purpose of improving ADL, but some patients are already accompanied by cachexia at the beginning of rehabilitation. At the start of rehabilitation, selection of exercise therapy type and exercise load is required according to cachexia level. However, the proportion of patients with cachexia at rehabilitation intervention is not clear.

Our study examined the incidence of cachexia at the beginning of rehabilitation intervention in patients with advanced gastrointestinal cancer.

*Corresponding author. Yoshiteru Akezaki (E-mail: akezakiteru@yahoo.co.jp)

(C)2020 The Society of Physical Therapy Science. Published by IPEC Inc.

(c) (1) $($ This is an open-access article distributed under the terms of the Creative Commons Attribution Non-Commercial No Derivatives cc. 


\section{PARTICIPANTS AND METHODS}

From January 2012 to December 2014, among 189 gastrointestinal medical patients who were prescribed physical therapy and occupational therapy by the doctor of rehabilitation medicine, patients where the survey item could be extracted were targeted. Patients in stages 1 and 2 were excluded.

Shikoku Cancer Center Ethics Committee approved the study, and written informed consent was obtained from each participant (Approval No. 2015-86).

The cancer cachexia assessment, ADL (Barthel Index; BI), and nutritional status were evaluated in all patients. Measurements of cachexia assessment, ADL, and nutritional assessment were performed at the start of rehabilitation.

For evaluation of cancer cachexia, Miki's modified Glasgow Prognostic Score (mGPS $)^{11)}$ was used. In this study, we classified into 4 groups: a normal group, a normal low-nutrition group, a pre- cachexia group, and a cachexia group.

Nutritional status was evaluated by the Geriatric Nutritional Risk Index (GNRI) ${ }^{12}$. From these GNRI values, four grades of nutrition-related risk were defined: high risk $(<82)$, moderate risk $(82$ to $<92)$, low risk $(92-98)$, and no risk $(>98)$.

Analysis of the ADL and nutrition among the groups was performed using Kruskal-Wallis tests, $\chi^{2}$ tests, and MannWhitney U tests. The SPSS version 22.0 software (SPSS Inc., USA) was used for data analysis. The statistical significance level was set at $\mathrm{p}<0.05$ for Kruskal-Wallis tests, and the Bonferroni method was used to adjust the $\mathrm{p}$-values for multiple pairwise comparisons ( $\mathrm{p}<0.05 / 6=0.008$ corrected for 6 pairwise comparisons) for the test after the Kruskal-Wallis tests.

\section{RESULTS}

Ninety-six patients (58 males, 38 females) were targeted. At the time of the study, the average \pm standard deviation (SD) age was $67.5 \pm 11.0$ years, height was $159.8 \pm 8.3 \mathrm{~cm}$, weight was $50.2 \pm 11.0 \mathrm{~kg}$, body mass index was $19.1 \pm 4.5 \mathrm{~kg} / \mathrm{m}^{2}$, time since hospital admission was $13.4 \pm 13.0$ days, and survival time was $212.05 \pm 218.9$ days.

The treatment was adjuvant chemotherapy for 46 patients and radiation therapy for 4 patients. The primary tumors were 31 colorectal cancers, 22 esophagus cancers, 12 pancreatic cancers, and 31 gastric cancers. The stage was patients in 21 in III and 75 in IV.

There were 15 patients in the normal group, 8 patients in the normal low-nutrition group, 16 in the pre-cachexia group, and 57 in the cachexia group. Characteristics of patients are outlined in Table 1.

The results of comparing ADL and nutritional status between the normal group, normal low-nutrition group, pre- cachexia group, and cachexia group are shown in Table 2.

Toilet use, bathing, mobility, stairs, and total score of Barthel index were significantly lower in the cachectic group than in the normal group $(\mathrm{p}<0.008)$. Grooming, toilet use, bathing, mobility, stairs, and total score of Barthel index were significantly lower in the cachectic group than in the pre-cachexia group $(\mathrm{p}<0.008)$.

GNRI was significantly lower in the cachexia group than in the normal and the pre-cachexia groups and significantly lower in the normal low-nutrition group than in the normal group $(\mathrm{p}<0.008)$.

\section{DISCUSSION}

Patients with pancreatic and gastric cancer have the highest prevalence and often develop the most severe degrees of cachexia $^{3-5)}$. In this study, the incidence of cachexia was $17 \%$ in the pre-cachexia group and $59 \%$ in the cachexia group at the beginning of rehabilitation in gastrointestinal patients who were referred to the Department of Rehabilitation. The cachexia group showed lower nutritional status compared to the non-cachexia and pre-cachexia groups. Because the patients in this study were stage III-IV, the proportion of patients with cachexia at the beginning of rehabilitation was considered to be high. At the beginning of rehabilitation in patients with advanced gastrointestinal cancer, it is necessary to evaluate the state of nutrition and cachexia and select exercise intensity in accordance with the possibility of pre-cachexia or cachexia. Also mGPS was useful for evaluating the cachexia level of advanced gastrointestinal cancer patients.

Muscle weakness ${ }^{13}$, reduced muscle oxidative capacity ${ }^{14)}$, premature fatigue ${ }^{15)}$, and diminished maximal oxygen consumption ${ }^{13)}$ have been shown to occur as a result of cachexia. In our study, the cachexia group showed significantly lower results in toilet use, bathing, mobility, stairs, and total score of Barthel index compared with the normal group. In the cachexia group, items using lower limb muscular strength such as toilet use, bathing, mobility, and stairs showed a significant decrease

Table 1. Characteristics of patients $(n=96)$

\begin{tabular}{|c|c|c|c|c|}
\hline Variable & $\begin{array}{l}\text { Normal group } \\
(n=15)\end{array}$ & $\begin{array}{c}\text { Normal low nutrition } \\
\text { group }(n=8)\end{array}$ & $\begin{array}{c}\text { Pre-cachexia group } \\
\qquad(\mathrm{n}=16)\end{array}$ & $\begin{array}{l}\text { Cachexia group } \\
\qquad(n=57)\end{array}$ \\
\hline Gender (males/females) & $11 / 4$ & $4 / 4$ & $3 / 13$ & $30 / 27$ \\
\hline Age (years) & $63.7 \pm 11.2$ & $64.8 \pm 15.0$ & $64.7 \pm 13.4$ & $69.6 \pm 9.3$ \\
\hline Treatment (adjuvant chemotherapy/radiation therapy) & $9 / 2$ & $7 / 0$ & $8 / 1$ & $1 / 22$ \\
\hline
\end{tabular}


Table 2. Comparison of activities of daily living and nutritional status between the non-cachexia group, pre-cancer cachexia group, and cachexia group

\begin{tabular}{|c|c|c|c|c|c|c|c|c|c|c|}
\hline \multirow[b]{2}{*}{ Variable } & \multirow{2}{*}{$\begin{array}{l}\text { Normal } \\
\text { group }\end{array}$} & \multirow{2}{*}{$\begin{array}{c}\text { Normal low } \\
\text { nutrition } \\
\text { group }\end{array}$} & \multirow{2}{*}{$\begin{array}{c}\text { Pre- } \\
\text { cachexia } \\
\text { group }\end{array}$} & \multirow[b]{2}{*}{$\begin{array}{l}\text { Cachexia } \\
\text { group }\end{array}$} & \multicolumn{6}{|c|}{ p-value } \\
\hline & & & & & $\mathrm{a}$ & $\mathrm{b}$ & $\mathrm{c}$ & $\mathrm{d}$ & e & $\mathrm{f}$ \\
\hline $\begin{array}{l}\text { GNRI (high/ } \\
\text { moderate/low/no risk) }\end{array}$ & $0 / 2 / 2 / 11$ & $4 / 4 / 0 / 0$ & $2 / 6 / 3 / 5$ & $39 / 15 / 2 / 1$ & $\mathrm{p}<0.001$ & 0.021 & $\mathrm{p}<0.001$ & 0.013 & 0.385 & $\mathrm{p}<0.001$ \\
\hline Feeding $(0 / 5 / 10)$ & $0 / 1 / 14$ & $0 / 1 / 7$ & $3 / 1 / 12$ & $7 / 17 / 33$ & 0.825 & 0.358 & 0.011 & 0.569 & 0.100 & 0.388 \\
\hline Transfers $(0 / 5 / 10 / 15)$ & $0 / 0 / 4 / 11$ & $0 / 0 / 3 / 5$ & $1 / 0 / 3 / 12$ & $5 / 5 / 21 / 26$ & 0.681 & 1.000 & 0.034 & 0.697 & 0.244 & 0.046 \\
\hline Grooming $(0 / 5 / 10)$ & $3 / 12 / 0$ & $1 / 7 / 0$ & $3 / 13 / 0$ & $33 / 24 / 0$ & 0.776 & 0.953 & 0.01 & 0.834 & 0.017 & 0.006 \\
\hline Toilet use $(0 / 5 / 10)$ & $1 / 1 / 13$ & $0 / 1 / 7$ & $1 / 1 / 14$ & $8 / 26 / 23$ & 0.975 & 0.984 & 0.004 & 0.976 & 0.014 & 0.002 \\
\hline Bathing $(0 / 5)$ & $6 / 9$ & $5 / 3$ & $5 / 11$ & $49 / 8$ & 0.400 & 0.716 & 0.001 & 0.204 & 0.126 & $\mathrm{p}<0.0001$ \\
\hline Mobility $(0 / 5 / 10 / 15)$ & $1 / 1 / 4 / 9$ & $1 / 1 / 3 / 3$ & $2 / 0 / 4 / 10$ & $18 / 6 / 20 / 13$ & 0.357 & 0.953 & 0.005 & 0.350 & 0.247 & 0.005 \\
\hline Stairs $(0 / 5 / 10)$ & $4 / 2 / 9$ & $3 / 2 / 3$ & $3 / 6 / 7$ & $40 / 10 / 7$ & 0.428 & 0.682 & $\mathrm{p}<0.001$ & 0.569 & 0.049 & $\mathrm{p}<0.0001$ \\
\hline Dressing $(0 / 5 / 10)$ & $0 / 2 / 13$ & $0 / 1 / 7$ & $2 / 2 / 12$ & $6 / 23 / 28$ & 0.975 & 0.545 & 0.009 & 0.610 & 0.042 & 0.131 \\
\hline Bowels $(0 / 5 / 10)$ & $1 / 0 / 14$ & $0 / 0 / 8$ & $2 / 0 / 14$ & $7 / 11 / 39$ & 0.825 & 0.984 & 0.070 & 0.834 & 0.067 & 0.056 \\
\hline Bladder $(0 / 5 / 10)$ & $0 / 1 / 14$ & $0 / 0 / 8$ & $1 / 0 / 15$ & $9 / 9 / 39$ & 0.825 & 0.770 & 0.046 & 0.653 & 0.067 & 0.184 \\
\hline Barthel Index (scores) & $86.3 \pm 18.9$ & $82.5 \pm 18.3$ & $81.3 \pm 27.5$ & $59.3 \pm 27.5$ & 0.466 & 0.770 & $\mathrm{p}<0.001$ & 0.697 & 0.021 & 0.002 \\
\hline
\end{tabular}

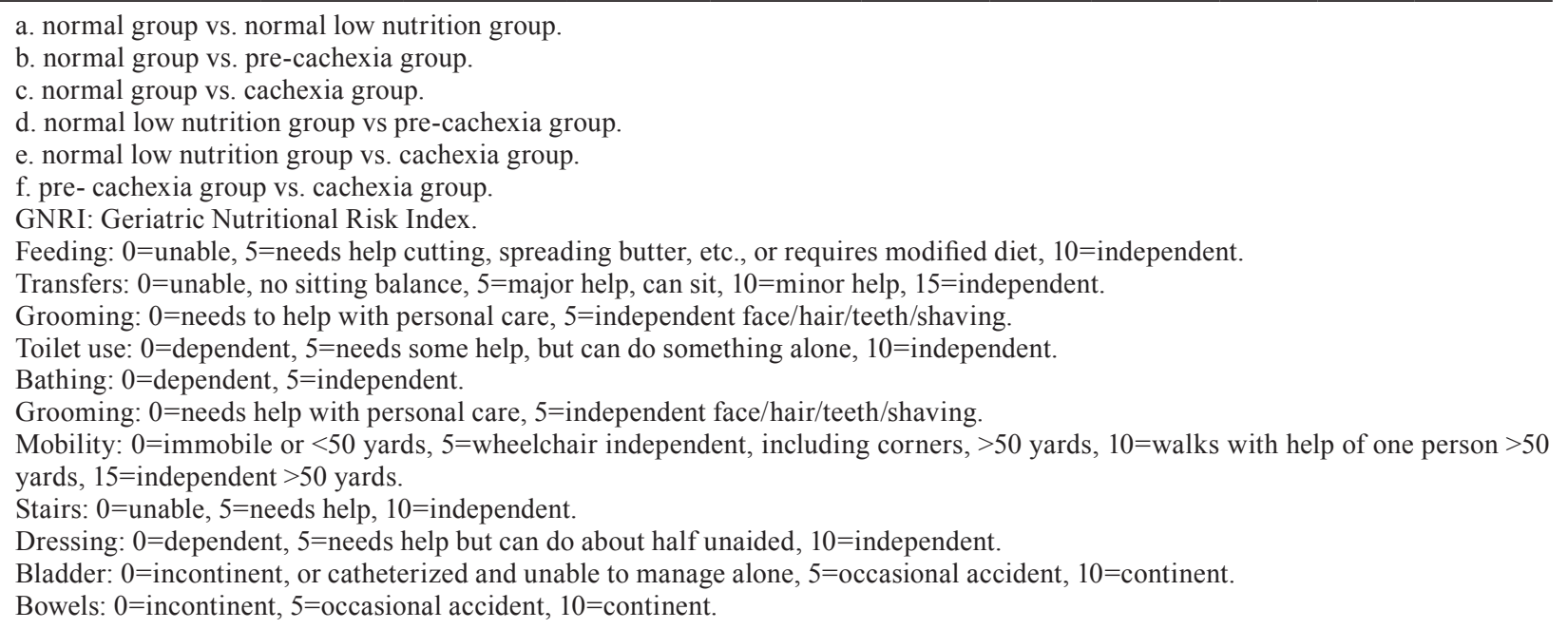

compared with the pre-cachectic group. Muscle mass is highly correlated with muscle strength ${ }^{16)}$. Several studies have shown that low muscle mass is associated with poor functional performance ${ }^{17,18)}$ and self-reported disability ${ }^{18)}$. Although this study did not measure skeletal muscle mass and muscle strength, the cachexia group may have decreased skeletal muscle mass and muscle strength. Therefore, patients of this study may have experienced a decrease in ADL due to decreased skeletal muscle mass and muscle strength in addition to fatigue due to cancer progression.

There were some limitations associated with the present study. For cancer patients, not only ADL but also QOL is important. However, in this study, we could not analyze how much QOL had declined because QOL was not measured. In addition, we performed the evaluation only at the start of rehabilitation, and we did not consider the effect of rehabilitation. Further research is needed to determine these influences.

\section{Conflict of interest}

The authors have no conflict of interests to declare in regards to this research.

\section{REFERENCES}

1) Fearon KC, Moses AG: Cancer cachexia. Int J Cardiol, 2002, 85: 73-81. [Medline] [CrossRef]

2) Argilés JM, Alvarez B, López-Soriano FJ: The metabolic basis of cancer cachexia. Med Res Rev, 1997, 17: 477-498. [Medline] [CrossRef]

3) Wigmore SJ, Plester CE, Richardson RA, et al.: Changes in nutritional status associated with unresectable pancreatic cancer. Br J Cancer, 1997, 75: 106-109. [Medline] [CrossRef]

4) Tisdale MJ: Mechanisms of cancer cachexia. Physiol Rev, 2009, 89: 381-410. [Medline] [CrossRef]

5) Tisdale MJ: Cachexia in cancer patients. Nat Rev Cancer, 2002, 2: 862-871. [Medline] [CrossRef]

6) Tisdale MJ: Biology of cachexia. J Natl Cancer Inst, 1997, 89: 1763-1773. [Medline] [CrossRef] 
7) Inui A: Cancer anorexia-cachexia syndrome: current issues in research and management. CA Cancer J Clin, 2002, 52: 72-91. [Medline] [CrossRef]

8) Fearon K, Strasser F, Anker SD, et al.: Definition and classification of cancer cachexia: an international consensus. Lancet Oncol, 2011, 12: 489-495. [Medline] [CrossRef]

9) Fouladiun M, Körner U, Gunnebo L, et al.: Daily physical-rest activities in relation to nutritional state, metabolism, and quality of life in cancer patients with progressive cachexia. Clin Cancer Res, 2007, 13: 6379-6385. [Medline] [CrossRef]

10) Kumar NB, Kazi A, Smith T, et al.: Cancer cachexia: traditional therapies and novel molecular mechanism-based approaches to treatment. Curr Treat Options Oncol, 2010, 11: 107-117. [Medline] [CrossRef]

11) Koike Y, Miki C, Okugawa Y, et al.: Preoperative C-reactive protein as a prognostic and therapeutic marker for colorectal cancer. J Surg Oncol, 2008, 98 : 540-544. [Medline] [CrossRef]

12) Rizzoli R: Nutrition: its role in bone health. Best Pract Res Clin Endocrinol Metab, 2008, 22: 813-829. [Medline] [CrossRef]

13) Weber MA, Krakowski-Roosen H, Schröder L, et al.: Morphology, metabolism, microcirculation, and strength of skeletal muscles in cancer-related cachexia. Acta Oncol, 2009, 48: 116-124. [Medline] [CrossRef]

14) White JP, Baltgalvis KA, Puppa MJ, et al.: Muscle oxidative capacity during IL-6-dependent cancer cachexia. Am J Physiol Regul Integr Comp Physiol, 2011, 300: R201-R211. [Medline] [CrossRef]

15) Aulino P, Berardi E, Cardillo VM, et al.: Molecular, cellular and physiological characterization of the cancer cachexia-inducing C26 colon carcinoma in mouse. BMC Cancer, 2010, 10: 363. [Medline] [CrossRef]

16) Landers KA, Hunter GR, Wetzstein CJ, et al.: The interrelationship among muscle mass, strength, and the ability to perform physical tasks of daily living in younger and older women. J Gerontol A Biol Sci Med Sci, 2001, 56: B443-B448. [Medline] [CrossRef]

17) Visser M, Kritchevsky SB, Goodpaster BH, et al.: Leg muscle mass and composition in relation to lower extremity performance in men and women aged 70 to 79: the health, aging and body composition study. J Am Geriatr Soc, 2002, 50: 897-904. [Medline] [CrossRef]

18) Sternfeld B, Ngo L, Satariano WA, et al.: Associations of body composition with physical performance and self-reported functional limitation in elderly men and women. Am J Epidemiol, 2002, 156: 110-121. [Medline] [CrossRef] 